D urante todos estos años, muy pocas veces he ido a otras partes invitado, en realidad los arquitectos nos visitamos poco, así que en realidad no se muy bien como dirigirme porque - después lo vamos a ver por lo que voy a decir - La arquitectura es un arte público, a diferencia de las otras artes. - bueno eso lo pueden ver - Los pintores puede tener sus cuadros en su taller, las obras de arquitectura están en la calle además entran y la ven, el suelo lo pisan todo, sin embargo a pesar de ser público los arquitectos están acostumbrados a hablar en la intimidad de los lugares en que trabajan.

Entonces, voy a tratar de ver como me dirijo, para lograr llegar a ustedes.

Les pido que me comprendan en eso. porque siempre hay que hablar de algo en particular Yo creo que sería bueno hablar en lo particular de esto.

La Arquitectura Hoy, se encuentra con que ha recibido del arte, de la técnica y de la ciencia del mundo actual, a diferencia del renacimiento por ejemplo lo que podríamos llamar la Libertad de Formas.

Una forma en la arquitectura actual no indica la próxima forma que va ha venir, a diferencia del Renacimiento, que mirando la forma se podía saber la formas que iban a venir, al contrario una forma, que viene, en la arquitectura actual es la innovación de la que ya existió.

Si todos en la arquitectura moderna quisieran ruinas, no podría con un solo trozo reconstruirse el edificio, sino que iría de innovación en innovación, este es el sentido pleno siglo o a mediados o finalizando el siglo $X X$, quedar situado en un plano en que el que actúa tiene la libertad de forma, de disposiciones de métodos constructivos de los procesos de producción.

En ese sentido se queda como todo hombre - el arquitecto manifiesta como hombre la condición humana - como todo sus oficios manifiesta la condición humana, cada cual lo manifiesta de una determinada manera, que lo vamos a ir viendo, palpando. Manifiesta entonces a quedar en libertad.

Precisamente ¿qué es una obra de arquitectura en la actualidad? Es una obra, un edificio cualquiera que en su hacerse se nota que se ha preguntado por sus libertades. Es un edificio eueleqtiera, pero que en el fondo denota haberse preguntado por sus libertades. O sea, hay que saber de forma, disposiciones ycon todo lo pertinente a ella, usos, costumbres, oportunidades, hay que saber de la técnica con todos sus avances y hay que saber de la producción para que la oportunidad que el reproducir se conjugue en oportunidad y sea adecuadamente bien llevada, pero piénsese esto, piénsese aquello aquí piénsese allá siempre va a denotar que se ha realizado un acto interno que el daba que quedo en libertad, que había estado en libertad y que tomo un determinado rumbo tomo determinado camino. Si esto recuerda que una obra tiene algo de lo que es casarse, de lo que es en la libertad de todas las mujeres posibles, de elegir una, eso, una obra seria como fruto de un casamiento, de una nupcia. fruto nupcial.

El siglo XX como quien dice se perfila, se coloca, se plantea en este asunto en primera fila, la primera

\title{
LA LIBERTAD DE FORMAS
}

DOI: 10.22199/S07198590.1998.0006.00002

\section{CLASE MAGISTRAL INAUGURACION DE LA CARRERA DE ARQUITECTURA}

realmente es una de las características de la arquitectura actual que la ha recibido de todo el movimiento creativo y espiritual de las artes, del pensar, de la ciencia y de la técnica, sobretodo de las artes

\section{Entonces este es un punto primero. La libertad de} forma.

De ello se desprende otro, punto que se encuentra a partir de ella, pero que también viene del momento actual. y de como se lleva la vida.

Es que los programas, las dependencias, las distribuciones, también son libres, hay una libertad de distribución de uso. Hay una libertad de colocación de las sillas en esta sala, alguien podría decir, mire no pueden colocarse las sillas así, no se puede colocar las sillas así, no se puede quedar de lado a un muro, i cómo se le ocurre ! o de espalda a una ventana, imposible no es posible. Hay libertad de uso y de disposición. Libertad de formas que engendran y llevan aparejadas

con una libertad de disposición, con una libertad de uso, espacios que se usan de una manera, otros de otras, que se cambian, flexibles, transformarles. La libertad de las transformaciones y la libertad de los múltiples usos.

Tal desarrollo de la técnica trae junto con ellos una libertad constructiva, pensemos en otras épocas sólo se podría construir con piedra, con un sólo material o como las antiguas arquitectura japonesas, entonces tenemos libertad de elección de los materiales más adecuados. Se encuentra, entonces con ese patrimonio y además los trabajos de la realización de la obra, con esos sistemas constructivos, con esos programas libres y en esas formas en libertad. Se pueden organizar según sean las condiciones, según sean las circunstancias, de esta manera o de otra, se puede entonces producir con procesos en libertad, por supuesto que la libertad es para hacerla con las leyes de la producción, con la mejor construcción, con los usos más flexibles, en la libertad de la forma, este es el patrimonio con que nos encontramos. cosa, de ahí vienen sus grandezas sus padecimientos $y$ en el asunto donde nos encontramos. Entonces vamos a ver que ha sucedido

Tenemos ( me van a permitir repetir bastante dado que son ideas muy simples muy elementales si uno las repite van cobrando cuerpo y se va saltando como a la piedra siguiente, ahora inicio como quien dice la piedra siguiente. )

Que le sucede si hay libertad de formas, si hay libertad distribución de programas de construcción de producción que resulta que hay libertad llamaríamos de otra cosa hay libertad de sí que alguien dice algo, dice un si, sí tal cosa, sí esto todos los sí son válidos, entonces es una mentalidad en lo actual en que todos los sí son válidos.

Valparaíso igual esta a la orilla del mar que Antofagasta, aunque he llegado ahora y lo conozco por primera vez y me están contando que hace poco tiempo se abrió la costanera. Alguien diría lo que Antofagasta tiene que hacer es abriese al mar y en Valparaíso igual lo que tiene que hacer este puerto esta ciudad su orden es abrirse al mar es una locura no hacerlo pero alguien viene y dice a mí se me ocurre otra cosa que en lugar de abrirnos al mar vamos a hacer otra postura voluntariosa también, le vamos a dar la espalda al mar vamos a tener el reverso del océano el reverso del vacío yo propongo eso. En Valparaíso por supuesto sin darse cuenta sin proponérselo, sin ninguna voluntad, se da el caso de que se viene por una calle que sube el cerro, son calles como los antiguos causes, (croquis en la pizarra) pero al subir aquí de repente puede pasar que viene este cause, los antiguos causes del agua. Por ahí suben los principales caminos siguiendo un orden natural dan una vuelta y una casa gusta de colocarse para acá dando la espalda al mar y gusta tener una entrada con un piso muy cuidado de baldosines todo cuidado en una penumbra delicada es una cosa natural que no se, pero alguien dijera yo voy a darle como misión no cantar el mar sino que cantar el reverso del mar y voy a cantar el reverso del mar o el anverso del mar y la espalda de el y voy a cantar algo 
de gran pulcritud y silencio. una arquitectura de silencios y de pulimentos y de acústicas yo voy a decir ese sí, digan ustedes el no y así se pueden decir múltiples sí.

Entonces nos encontramos en un mundo, los arquitectos la siguiente cosa que estamos en un régimen de libertad creativa, en cuanto son formas en libertad son programas en libertad y a la vez esta libertad creativa se encuentra con todas la voces que surjan afirmando algo coherente con sigo misma es válido, nos encontramos entonces en un panorama riquísimo y a la vez desconcertante como se procede en esto, como se procede como si hubiera un bufete monumental con toda clase de mariscos productos y comidas pase usted a comer entonces no sabría como hacerlo entonces me parece excesivo sin embargo es así es así pero es más lo que hay en la actualidad es más la abertura de libertades y es más donde tenemos que hacer y tenemos que construirnos a nosotros mismos nuestra propia voluntad de hacer algo porque entre más se abre la posibilidad más nosotros tenemos que sacar fuerzas de nosotros mismos tenemos más cavilar juntarnos entre varios consultar hacer lo que queramos, juntarnos a ver aquí, acá para tomar en este mundo que ofrece esto la validez de todos, todos en potencia igualmente interesante.

Es evidente que si hay formas en libertad todos son igualmente válidos en principio puede que unos sean mejor o peor desarrollados pueda ser que esta obras sean mejor estas obras peor pero todas tienen igual calificación tienen igual derecho tienen modos de hacerse oír ya vendrán otros que lo harán mejor no se puede ser por la calidad sino que por la legitimidad

\section{U. C. N. ANTOFA G A STA 1982}

de estos ahí nos encontramos en esta situación.

Pero, no paramos aquí el asunto es más que esto, en este momento arquitectónico, en esta segunda mitad del siglo XX, en esta segunda mitad después de 1950 no importa precisar con mayor en estos momentos esta vigente, desde hace unos diez años, mas o menos surgen arquitectos y son los que hay más, sin decir que son los mejores pero son dominantes es lo que hay más que piensan que hay una libertad de abstracción en un tiempo se pensaba que la arquitectura moderna o sea la válida, la real arquitectura era como esta ascética de puros planos sin decoraciones, hoy día hay algunos que piensan, no solo algunos todos, piensan que es posible que haya decoración que traigan otros elementos que se le coloquen allí para significar cosas , para significar estilos habidos, y la mezcla de todos . la mezcla de todo lo anterior, tomarlos todos con su suavidad o con violencia pero poderlo mezclar y ser dueño de todo lo que ha sucedido y colocarlo en una obra, por que sí, es una libertad como si uno llegara a su máximo si pescáramos esto le sacáramos el techo a esas casas antiguas de Antofagasta y se la

colocáramos encima y este edificio sea de una época, como quien dice con el aire de una época o con la forma de una época o con la forma de otra época y todas entre mezcladas tendría una significación porque la arquitectura es dueña de la abstracción para hacerlo o sea es la libertad de abstracción, ese es el asunto nosotros entonces nos encontramos ante eso los sí han sido llevados a ese extremo, a sí hay los que se han llamado a sí mismo los Post-modernismo y el NeoModernismo, se plantean en esas cosas que para un modernista le parecerían inadmisible, y a ellos les parece admisible y si alguien les digiera que es una ocura los llevarían al caso anterior de que todos los $s i$ son válidos, y que todos los amparados en la gran nota creativa de la época en que vivimos del siglo XX que ha sido tan creativo en todo, es el siglo eminentemente creativo y yo soy hijo de mi siglo y en nombre del hijo de mi siglo yo usufructo y fructo y fructifico toda estas cosas que estoy aquí, entonces nosotros los arquitectos nos encontramos ante eso, uno pueden decir que no le da frío ni calor el asunto pero la situación es esa y quiéralo o no lo quiera esta colocado en ello aunque diga que no esta colocado esta colocado, esta colocado o sea nosotros históricamente estamos colocados en ello no somos medievales, no somos renacentistas no somos de comienzo de siglo, somos del momento que somos y ese es el momento que plantea esto que hacer de esto esa es la labor de cada arquitecto cada uno de aquí puede tener la suya por supuesto que cada arquitecto puede variarla puede adoptar una primero o provisoria después tantear después ir mejor, después mejorar y después volver de nuevo emprender la marcha de nuevo encontrarse con otro ver, en fin cada uno puede seguir la marcha que encuentre oportuna porque de todas manera su marcha va a ser esa y alli aparece que el que sostiene algo queda muy superior al que no sostiene nada. sostenerlo quiere decir en una igualdad o una permanencia o invariable sostenerlo quiere decir que vive esta preocupación y quiere afrontarla y decir algo, no tiene porque ser la voz personal de él puede ser la de un grupo puede ser que diga yo hago lo que haces tu en fin esa es la vida. este es el asunto primero, todas las escuelas todos los arquitectos todas las oficinas todas las actividades se quedan en este asunto conozcan más el asunto o lo conozcan menos sepan más tengan ideas más claras ese es el asunto.

Ahora bien yo sin pronunciarme porque en esto somos todos igualmente libres así que yo no estoy aquí hablándoles a ustedes porque tuviera coherentemente una cosa superior yo le estoy contando no más en lo que estamos y yo me pongo a contar en lo que estamos,como si digiera estamos a la orilla del mar ya lo sabemos bueno ya lo sabemos por eso digo que es una intimidad

\section{ALBERTO CRUZ COBARRUBIAS.}

estamos hablando para nosotros y contándonos en lo que estamos

nos estamos sonriendo entre nosotros contándonos las cosas en lo que estamos alguien puede decir usted exagera bueno exageremos menos pero el hecho es ese.

\section{Segunda parte}

Que tiene este hecho ¿cuales son las luces y sombras de este hecho? hay una cosa curiosa es la siguiente a comienzos de siglo Le Corbusier y Frank Lloyd Wright , Alvar Alto, Gropius, Mies Van der Rohe en fin los grandes arquitectos no vivieron un momento de puro si tenia no, la diferencia fundamental que ha habido entre Le Corbusier y nosotros es que Le Corbusier era con no y el momento actual es con si. Entonces Le Corbusier con su no montaba en cólera enfurecido de furor poético con sus no, no hubiera aceptado jamás cosa por el estilo, entonces espiritualmente nos encontramos en la siguiente cosa que somos distintos a la época anterior nada más o por muchas otras cosas más pero lo que aquí importa es que esa época era con no y si, un manifiesto es un si a tales cosas y un no a tales otras y hay de los que están luchando para que eso no prevalezca guerra contra ellos desgraciados mala fe viboras etc fuera con ellos entonces pasamos de un mundo de si y no a un mundo de sí ese es el asunto, ahora bien que sucede en un mundo de puros sí y en un mundo no esta es una reflexión que yo me hago todo lo demás tendría que ser firmado por todos hay documentación para leerla, pero ahora voy a decirles una reflexión que yo se las comunico yo a ustedes, la reflexión es la siguiente: que cuando todo es si y todas las cosas se pueden hacer vivimos el mundo de posibilidades, vivimos en el medio de lo posible y no en medio de la libertad creativa, estamos hablando de la libertad creativa estamos hablando de la creación piénsese lo que se piense de ello. y en el otro estamos situados en el mundo de la posibilidad hay una diferencia entre una libertad creativa y una posibilidad creativa.

Ese es el punto que hay que tomar en cuenta entonces la libertad tiene si y no y la posibilidad tiene 
puramente si, entonces a nosotros nos ha pasado que tenemos que reconstruir la Libertad Creativa habiendo heredado todo !ohi que paradoja la hemos recibido como posibilidad y tenemos que volvernos para nosotros a nuestra interioridad para todas las posibilidades volverlas libertad, aquellas que tenían los otros cuando decían que no. Yo no digo que nosotros no podamos decir que no porque cada época dice su cosa, luego internamente nosotros estamos aun abocados en el interior de nosotros mismos a decirnos que tenemos que reinventar como nuestra creatividad es libre como si cada época tuviera una figura una forma de su propia libertad creativa y que nosotros tuviéramos que rehacerla de nuevo como un hijo que hereda todo de su padre menos que hacer en la vida es decir no como comportarse en la vida por eso comienza en el caso del amor comienza lo misma a eso de los catorce años no sirve de nada la experiencia de su padre para el primer trato con una mujer no va a ser con un hombre no sirve de nada tiene comenzar de nuevo a crear una cosa así hay que crear porque la arquitectura es el trato del edificio con su propia libertad entonces tenemos que inventar recoger cada cual como quiera echando a mano lo que se le antoja como toda obra ustedes saben que las obras al final se hecha a mano lo que fuere con tal de poder realizar unos techos y unos muros. Así mismo aquí se hecha a mano a todo para encontrar la propia libertad y no quedar en la simple elección y luego encontrar nuestros propios no por supuesto que esto es inédito y los esfuerzos tienen que ser múltiples aquí hay propaganda ...en un lugar comienzan unos jóvenes ahí a plantearse estos asuntos ...

Entonces alguien podría preguntarse porque nos
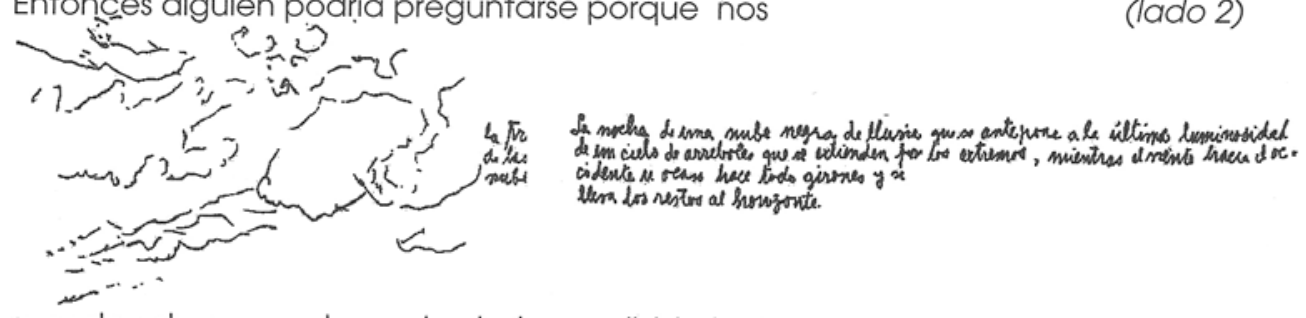

sucede esto que mala suerte haber recibido todo este inmenso caudal poético como quien dice casi la cola de un cometa fabuloso y se que nos deshaga en la mano, no es que se nos deshace en la mano es que la luz de un cometa nos invita a hacer otra cosa a no ser unos pasivos herederos sino que de nuevo ser unos creadores. Siempre es un problema con la creatividad.

Entonces que diferencia mas hay, Le Corbusier y los anteriores a el tuvieron una guerra a muerte, eran luchadores polemistas tremendos icon quienes tuvieron que habérselas? tuvieron que luchar con el poder para imponer la arquitectura que ellos veían ellos quisieron transformar el mundo en el sentido que el mundo se construyera en adelante con las formas en libertad que ellos veían y la batalla a los hombres de esta guerra los animaba les daba sentido a todo cuanto hacían muy bien y resulta que en líneas generales como en todas las cosas humanas ganaron ellos y se hacen los edificios que ellos dicen en líneas generales ya no hay ningún problema ya esta instalado así que nosotros hemos recibido la situación de no vivir para hacer la arquitectura en un guerra sino que en una paz, entonces en lugar de ese furor nuestro creativo ser de guerra es de paz, luego nosotros tenemos que crear y estado de paz artística no estamos contra ni para cambiar el mundo, ni el cliente es enemigo cuando quiere hacer todas cosas, las formas en libertad al contrario entonces que difícil es administrar en esta situación, lo que parece favorable es lo que nos aprieta la garganta ahora lo que pensábamos que era lo fácil lo fecundante es lo que es difícil cualquier poder es muy difícil de tratar, la arquitectura tiene que hacer con el poder, hay que tener poder para conformar formas si uno no tiene una cabeza potente capaz de hacer forma sino tiene potencia no hace nada tiene que tener cabeza potente e inteligente y capaz no es cierto para comprender los programas y tiene que tener algún trato con el poder para que le de o sino no lo mandan a mirar jamás y no hace nada, tiene que tener potencia y contacto con el poder de los constructores y el poder de los productores o sino no lo construye no produce nada, no se puede hacer un edificio en altura de veinticinco pisos que necesita el poder de dominar la naturaleza, entonces hay un dominio interno de la forma y hay un dominio externo de la naturaleza y de las operaciones constructivas entonces lo que nosotros tenemos que ver es la relación de la arquitectura con el poder para manejar la forma para manejar los casos para manejar el dominio de la naturaleza, ustedes comprenderán que el dominio y el poder de este siglo para construir edificios en altura gigantescos que significa un dominio particularmente en Chile sobre los sismos o el poder que tiene para hacer de la noche día como ahora, para hacer de las estaciones del verano invierno por la refrigeración y el invierno verano por la calefacción esa potencia técnica de casos e interno de forma es habérsela con la forma la arquitectura es eso es un arte que tiene mucho que ver con el poder.

Entonces nosotros estamos en este instante en una cosa que el poder no es contra nadie, nadie lo disputa entonces nos encontramos con el poder en las manos, cuando a un arquitecto le niegan el poder le saltaría como un pájaro de presa, para lograr arrancar el poder para poder realizar, pero el poder lo tenemos, por eso digo que estamos en paz, tenemos que tomarla que, significa en la creatividad arquitectónica el poder esa es la meditación de la segunda mitad del siglo XX .

Una sola cosa no se le puede tomar como una cosa mecánica, como una mera cosa mecánica hay que reflexionarla hay que medirla, cada cual meditara acerca del poder como le parezca pude que lo medite muy mentalmente o en los hechos o en la practica tanto internamente como externamente. (lado 2)

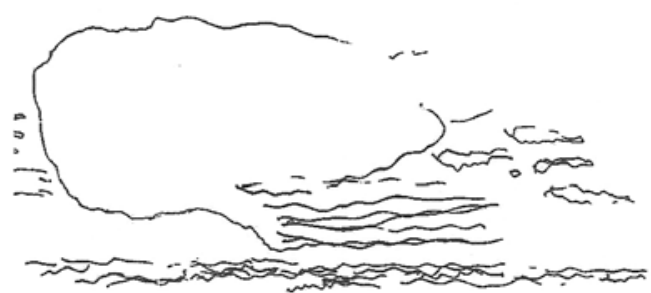

Si y No, Es muy bonito esto porque se supone que a la técnica no se le puede decir que no, o se le puede decir que no a una estructura, sin embargo más allá de eso es necesario preguntarse porque la creatividad en nosotros nos pregunta por la relación del mundo y precisamente por no preguntarse eso y darlo por un hecho obvio que no habría que hablar nada de el es que precisamente por eso es que esta cola de cometa inmensa se nos transformo de libertad en posibilidad. Pero esto no es para que nosotros nos hundamos estas son las peripecias de este linaje de los hombres que son los creadores que van siempre en esta peripecias. este es el cuadro, el cuadro podría pensarse que esta finiquitado aquí, antes de que yo pudiera decirles ciertas cosas como yo estoy reaccionando pero antes hay otras cosas que son importantes entren estas libertades.

Hay la libertad de fundar algo, hagamos un centro de estudios, reunámonos porque si un día si ahora a la salida que fuera una reuniéramos en una sociedad permanente que se llamaría para la arquitectura, o por la arquitectura, o con la arquitectura tenemos absoluto derecho pero ustedes son unos locos porque de donde cree que no podemos, le parecerá que somos tontos pero no le puede parecer un sin sentidos.

Entonces los arquitectos no la arquitectura y - con esto comienzo como tres puntos finales sobre los arquitectos y no la arquitectura- haciendo como un distingo pueden fundar los centros de estudios las organizaciones, las revistas, las investigaciones, lo que quieran como quieran y donde quieran etc., no hay ninguna regla previa entonces hay una fecundidad desatada, inmensa que características tiene que tener esa, una característica muy importante que es la relación con todo lo anterior, alguien va por aquí y dice mira esa casa a mi me gusto pero alguien dice oye no le encuentro ninguna gracia pero hay algo que a mi me dice eso pero a mí no me dice nada. a mí me ayuda, no me ayuda, me desata cosas, me dan ganas de hacer cosas, me dan ganas de hacer cosas que se me ocurren tengo una relación con ella no la voy ni a copiar ni a seguir quizás piense distinto la voy a 
desmentir pero ella se mete conmigo uno vive siempre atrapándose con cosas que se meten con uno yo quisiera zafarme, pero no puedo se me metió adentro, el pasado no esquemáticamente sino por puntos muy precisos se nos mete adentro, no lo puedo echar esos son los que se meten adentro podríamos llamarlo y ponerle un nombre son originales. Se ha fijado que cuando vemos un dibujo alguien dice no bueno este no es un cuadro es un original uno se encuentra como si fuera con la carne viviente del cuadro no es reproducción, es el original entonces hay millares de casas como si el resto de la ciudad fueran puras reproducciones, puras reproducciones y aparece de repente uno que es un original entonces uno el original lo toca, el original lo toca se ha fijado que es distinto cuando- ustedes a lo mejor lo pueden decir mejor que yo- va una persona y oye música, pero de repente va oye tocar piano, pongamos un músico moderno Schömberg oyéndolo, viendo al pianista tocar ve los silencios - ha le cambia la cosa, , ve la música con su carne, así nos encontramos en millares de aspectos, Schömberg también que se yo, no solo de arquitectura sino que la constelación de originales con las cuales nosotros tenemos una relación, no somos ni hijos, ni padres, ni nietos, ni madres, ni amigos ni nada, sino que estamos tocados por ellos y además no los seguimos ni los seguimos es una relación misteriosa, - pero existente muy misteriosa pero existente - lo bonito es que no depende de nosotros somos visitados por ella, entonces nosotros tenemos este asunto de fundar para entre muchos quedar, como quien dice juntarnos en torno a la constelación de originales con lo cual nosotros viviremos con lo cual nosotros surgiremos y con los cuales haremos nuestras vidas, por supuesto que se cambian, se olvidan se vienen etc. y esa es
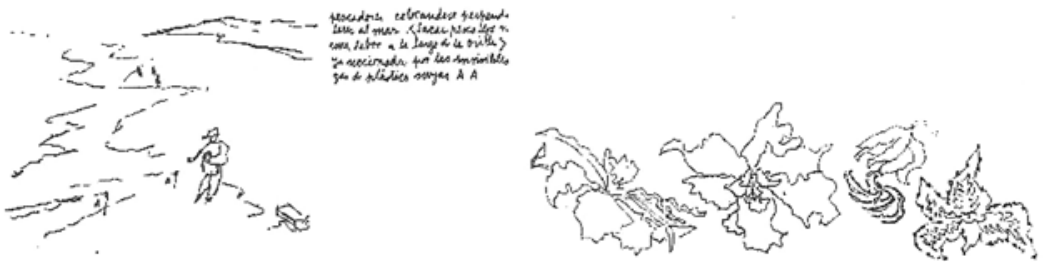

una libertad que hay en la actualídad, por supuesto que esto es lejos de la mera erudición por supuesto que hay que saber muchas cosas para caer en esto pero de repente con saber tres o cuatro cosas se le cierra a uno las compuertas de la erudición y de repente descubre otras etc. además tiene una vista libre no es cierto.

Ahora hay un gran original para la arquitectura es que nosotros somos, el gran original nuestro es Grecia. Esto es difícil de probar así, podríamos decir que nuestro origen es Grecia, y es nuestro origen porque es nuestro original, y cual es la característica de Grecia. Grecia tenía libertad creativa y no posibilidad y por que tenía libertad creativa tenía dos artes públicos que era la Arquitectura y la Tragedia ella tenia esas dos cosas, cuando no hay polis o ciudad no hay arquitectura ni hay tragedia representada. ! ah cómo vivir en esas épocas. bueno afanándonos para que la ciudad tenga esa vida que tenía la polis griega, y era que precisamente fuera público el asunto , - que sea público el asunto- público el asunto- que el hablar en sí mismo se torne un elemento público en el cual plantea lo que es la diferencia entre la ciudad viva y la diferencia entre la mera posibilidad y la elección de la libertad, en esa grandeza vive la arquitectura y siempre esta trabajando para ello sépalo o no lo sepa, quiéralo o no lo quiera, y siempre esta añorando, y cuando se lamenta todas las reuniones de arquitectos lamentantes, dolorosas y llorantes que son las más no es cierto en el fondo, la última cosa que no se atreven a decirse - jah si viviéramos en una ciudad que fuera realmente una ciudad, que fuera realmente un polis y nosotros tuviéramos tragedia y tuviéramos arquitectura pública, esa es la condición del hombre para eso es la arquitectura para marcar eso cuando no lo hay, ninguna de estas cosas que estoy diciendo adquieren la plenitud, pero nosotros no vivimos en esa época, y que hacemos entonces cada uno luchará se empeñará, lo buscará como lograr este asunto, pero nadie puede bajarse aunque no lo sepa. Esta es la segunda condición de los arquitectos.

La Tercera condición actual es esta y es muy importante en la etapa - En medio de las cosas de la vida los arquitectos actuales haciendo y hablando tienen que todo transcurre en el fluir de las cosas, en el fluir de las cosas, voy hacer una cosa me voy a empeñar en esto como construir todas estas cosas- y si el fluir de las cosas podríamos llamarlo es eminente mente oral pero ahora porque antes no había se a multiplicado, los libros, las editoriales, los congresos, etc. etc. etc. Ias bienales, que pretenden ser las bienales, pretenden meter que todo este cavilar escrito, porque lo escrito fija y lo oral deja el pasar, al pasar, por ejemplo alguien le podría decir - yo voy en una pisadera de un auto - y al pasar a otro le grito oye no se te olvide si no hay tragedia no hay arquitectura. hasta luego me voy, no me vas a ver nunca más felicidades, en lo oral queda allí el pensar, en lo escrito, de paso por escrito lo toma lo lee y lo guarda. durante mucho tiempo la arquitectura desde siempre y en el Renacimiento comenzó a debatir el asunto del lenguaje oral y escrito en el cual el penar mismo es fijante , ( voy a poner un ejemplo en el cual ustedes van a entender.).

Una fachada del renacimiento, era lo siguiente adentro la casa tenia diferentes dependencias que daban unificadas por ejemplo en los palacios italianos en un solo plano hacia afuera un solo plano hacia adentro varias dependencias, lo múltiple se fijaba en lo uno, y no aparecía en su multiplicidad ese era el pensamiento del renacimiento que era el sentido de fijar la cosa, en ese sentido era eminentemente - para los efectos en que estoy hablando- como escrito, en la fijación de las cosas.

Entonces fundar en la libertad ante los originales, fijar en la libertad ante el lenguaje oral y escrito,

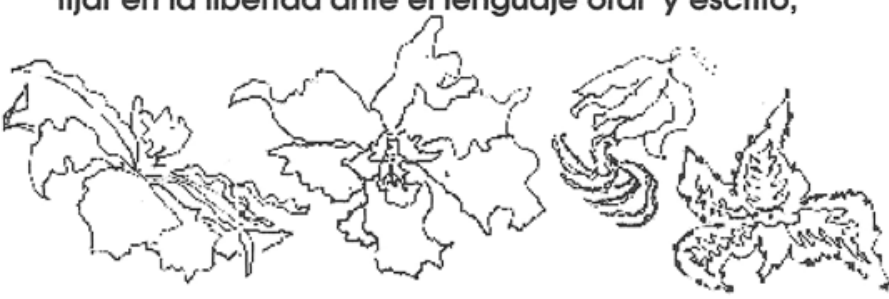

estas tres cosas le pueden ayudar a los arquitectos

en sus si y no, es un camino -a mi juicio - son

situaciones, son gradas, si quiere son plazas, para recapitular en una cosa más arquitectónica, para caer en la cuenta de: libertad y posibilidad del momento actual, este minuto es fúndante en la arquitectura actual, las cosas que estamos viendo ahora, por eso estamos reunidos. Para terminar quiero decir una cosa, sobre la arquitectura misma y que todos van a convenir y van a entender para atrás, si las demás fueron consideraciones de la arquitectura este es el meollo de la Arquitectura en carne y hueso, como quien dice adentro,

Que es un cuadro, un cuadro de Picasso, Picasso pesca un cuadro y lo pinta con su mano, la de Picasso pincelada por pincelada, no hay pincelada de otro, es la mano con la tela, ahí por la mano le sale el genio de Picasso que lo distribuye en la tela las cosa, no hay nada en el cuadro que no sea de Picasso. El propio Picasso una vez le decía alguien, yo no soporto a la persona de Chagall, pero hay una cosa que hay que admitirle, a este hombre que pinta sus cuadros enteramente él, entero hasta los últimos rincones, la arquitectura también las obras, son edificios enteros hechos por la voluntad del arquitecto. vale decir no hay nada que sea s resultante, él ha sabido toda las condiciones, todas las posibilidades, todas las libertades, todo lo que puedan decir los demás, todo lo que puedan influir todos, en un arte mágico, en hacerla suya, de manera que no hay nada resultante, es precisamente, que es la arquitectura es un edificio que tiene la voluntad de ser lo que es, eso es todo, el Partenón admira tanto porque hasta la última estría quizá sea el único edificio en el mundo que logró tal cosa, es palpitante de su propia voluntad, y porque es palpitante de su propia voluntad puede dejarla remitida en una zona en la cual se dejan todas las cosas plenas cuando los hombres ni siquiera son manifestantes están allí detrás, , eso es una cosa, pero la arquitectura es eso entonces que pasa,.

En el momento actual todos los arquitectos pasan por un dilema, hay la posibilidad de que yo comience por lo cierto por los límites, por estos limites, por este límite. 
Por el otro límite y por los límites interiores y el espacio interno en donde nosotros estamos reunidos y que nos alberga es la resultante de estos otros, que esta hecho muy bien, con hermosura, con juicio, con honestidad, con sabiduría, con calidad, pero el interior es resultante. Ese es un drama, alguno lo encontrará que esta perfecto pero tiene que admitir que en la mitad del asunto es resultante, no puede criticarse, aquí no vale la cosa, vale la libertad, hay otro que podrían decir yo lo tengo en el centro, yo tengo el orden en el centro y salgo a buscar mis muros, salgo a buscar mis tabiques y voy a buscar tabiques que convengan a $m$ interior, no voy a usar ningún tabique, ningún muro que no convenga a mi interior, yo calcule que a este interior para oír qquí le conviene, mucho que el tragaluz de esa ventana sea esbelto mire, por esto, por aquí. por acá, no hay resultado de nada, lo salí a buscar, bueno tengo que admitir que no me resulto, eso no importa, entonces eso es una cosa se produce donde y como se da en la arquitectura actual la voluntad de ella misma por ser el modo como la creatividad se crea así misma, en sus posibilidades ser, lo mismo vale para el urbanismo. Ahora bien en general, si uno sale a mirar las obras de arquitectura y quisiera hacer una crítica de ellas, cosa que no es el momento y no viene al caso, lo que más llama la atención, es interior que no se corresponden a sus límites, es que el interior que el espacio que los huecos correspondan con sus límites, que para muchos les parece obvio es lo que no tiene nada que hacer, si los arquitectos se sentaran todos en el medio de los espacios que están inventando y miraran como van a ser las cosas, esas serian las cosas, si lo miran aun cuando con la intención que tengan todo le resulte todo pequeño torpe, defectuoso, o malo fracaso esas

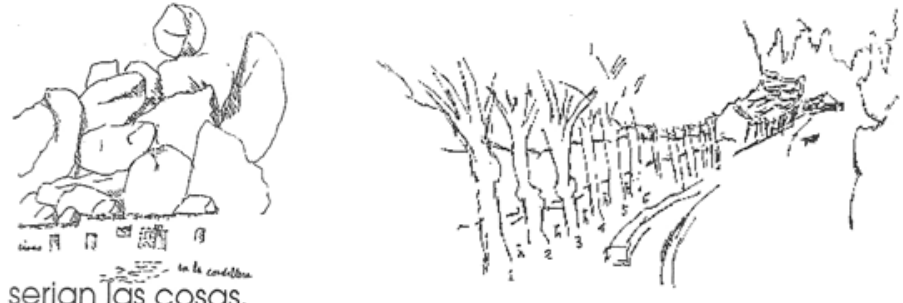

Entonces, hay muy pocos ejemplos de eso. Valparaíso, tiene fama de ser aquí y allá la calle hay que ir a verla ustedes pueden ir a verlo(calle que suben a los cerros) ustedes saben toda las cosas y muchos piensan que la escuela de arquitectura de allá esta en los cerros porque tiene la arquitectura, -bueno- En realidad yo pienso que hay una sola obra en Valparaíso, -una- que si un día van a Valparaíso, tengo mucho gusto en mostrarla la de los cerro, en el sentido que lo interno es coherente con lo externo pero no como el Partenón en su totalidad. no como el Partenón en su totalidad sino que nada más en algunas partes, cual si nosotros nos propusiéramos ser unos sixtinos, esta coherencia a nosotros nos cuesta tantos trabajos, y tantas cosas tanto y todo lo anterior que hemos estado trabajando que lo hemos logrado en un punto. no podemos pretender más no quiero decir que nos viéramos felices, podemos quedar sollozando, pero la creatividad es la creatividad. no porque nosotros nos autofelicitemos el asunto va a estar logrado, o porque digamos que hemos avanzado mucho de una obra a otra ! no i nosotros somos medidos por las obras, yo también conozco otra obra en Santiago que otro día podría decir donde esta, es una obra en que realmente se pensó en toda la obra esta echa en base a producir la profundidad, se va de profundidad en profundidad, es una casa chica pero no se como se logro endiabladamente que siempre estamos en situaciones de profundidad, porque los anchos y los largos y el

suelo mañosamente esta en pendiente por que es un poquito en un cerro en los alrededores de Santiago y logra eso. entonces quiere hacer, va a buscar sus límites y resulta que en verdad, que ni los cielos. tienen coherencia con esta profundidad que desea, ni los muros tienen coherencia con esta profundidad que desea, ni los pisos tienen coherencia con el, pero entonces que diablo tiene si no tiene ninguna jah ! tiene el paso del cielo al muro y el paso del muro al piso como dos horizontes entonces es una cosa que nada más se lo logra en esa zona de ajuste de los horizontes, se los digo,es una cosa macanuda. Es así a míme parece que la voluntad no desfalleciente de la creatividad en los ofrecimientos de la libertad, en que tenemos que aprender los no, los nuevos no para constituir esas nupcias en que no entran los arquitectos este es el asunto del momento actual en la reflexión del poder por supuesto que no para disminuir arcaizante los ofrecimientos que hace la técnica sino que para recibirlo en un modo que se va hacer voluntad propia nuestra.

Hice una alusión al urbanismo -término con una cosa del urbanismo moderno. Ustedes saben una cosa histórica pero muy elemental de colegio, una cosa de colegio.

Cuando América se descubrió que los cartógrafos la pintaban más cuadrada, porque no se conocían hubo que dividir las tierras conquistadas en regiones, llamadas en ese tiempo gobernaciones ellos la dividían en gobernaciones paralelas Santiago, Valparaíso y Buenos Aires Mendoza, quedaban en la misma gobernación. porque el rey Carlos $\vee$ dividió así, porque en ese tiempo tenían mucha importancia lo que se llamaban la franja del clima había lo tropical lo semi- tropical, lo pre-templado, lo templado lo postemplado y lo frío, pero además las líneas eran parejas. rectas paralelas, por que la forma tenía que ser perfecta, como la plaza de armas que era un vacío no edificado al centro de la ciudad era perfecto , Ia ciudad se organizaba al rededor de la perfección', esta no se edificaba, sin no la traza el rey, era lo perfecto era una forma perfecta, quería arrogarse ese título por ser perfecta. después los conquistadores siguieron otros caminos y accedieron por aquí, por acá y se penso con esto que había que hacer en lugar de las trazas perfectas, dividir por ejemplo según las aguas, o las mas altas cumbres, exactamente por ellas en lugar de la perfección es la exactitud, división

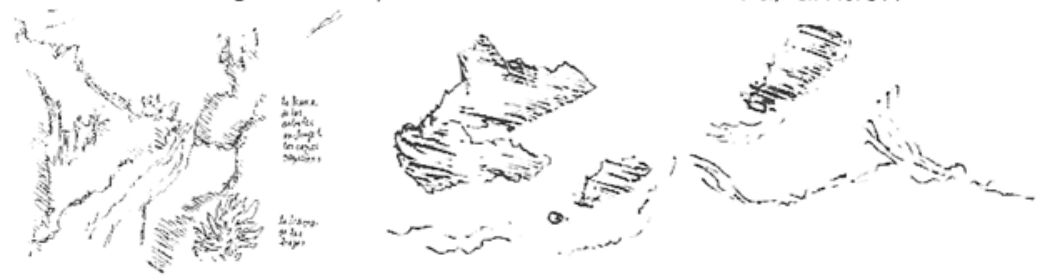

exacta porque estamos en el momento de acceder exacto el avión que me trajo tiene que exactamente aterrizar ahi si aterriza tres cuadras más allá en nombre de la perfección no sirve entonces vivimos en un tránsito en el urbanismo de la perfección a la exactitud o de la exactitud a la perfección y nosotros tenemos que debatir en el fondo en nuestros pies que lo pisan perfección o exactitud entonces el urbanismo bien o mal llamado que dice del orden de la ciudad o la tierra viene a plantear y a sumar una libertad más alguien podría decir yo soy partidario de la exactitud o yo soy partidario de las demás cosas o yo soy de las dos cosas juntas. yo descubría algo que es de las dos cosas juntas a la vez, entonces esa es mi clave y desde allí avanzo para allá o retrocedo para acá eso depende de la eficacia de la escala de la cosa, de la escala humana, de la concepción que cada cual tenga de la escala humana porque- y esto es lo últimodetrás de todo el debate el que lo permite en la arquitectura y el urbanismo es el debate sobre la escala humana, cual es, esta, la de la plaza, la del edificio la de acá o todas juntas y en que relación está

Saben, que lo que he hablado es como un temario de asuntos, yo he encontrado que es bueno un temario de asuntos, es de arquitectos, ¿qué es un temario de asuntos? es abrir entre nosotros mismos una plaza en la cual cada cual puede cruzar en el sentido que quiera y dice lo que quiere y otro dice otras cosas pero hay la plaza, mi intento ha sido entonces esta tarde construir una plaza. 